\title{
El desarrollo \\ de una investigación etnográfica en la comarca de Buitrago (Madrid)
}

\author{
MATILDE FERNÁNDEZ MONTES \\ Departamento de Antropología. CSIC. Madrid
}

\section{RESUMEN}

En el artículo se narran las vicisitudes acontecidas durante la realización de un estudio etnográfico de carácter general, centrado en la comarca de Buitrago: A) Fases iniciales (elección del área de estudio, financiación, primeros contactos, etc.), B) Periodo de acopio de documentación (bibliotecas visitadas, autores y bibliografía de interés) y C) Desarrollo del trabajo de campo: instalación en el lugar, primeros contactos con los informantes, metodología y estrategias empleadas para obtener información, dando una visión personal y autobiográfica de los problemas y soluciones planteados.

Palabras clave: Métodos antropológicos, Sierra Norte (Madrid), Trabajo de campo, Informantes.

\section{SUMMARY}

This paper explores the circumstances involved in a fieldwork set in the area of Buitrago: A) preliminaries (how the site was chosen, how the funds were got, how first appointments were made), B) documentacion (libraries, authors and references of interest), and C) Development of the fieldwork itself: getting into the site, first appointments with informants, methods and strategies used to gather information, and finally problems and solutions from a personal authobiographic perspective.

Key words: Anthropological Methods, Sierra Norte (Madrid), Fieldwork, Informants.

\section{INTRODUCCIÓN}

Cuando Margarita del Olmo me invitó a participar en el XXII Curso de Etnología, Julio Caro Baroja, seleccioné como tema de exposición, uno muy próximo a mi trayectoria actual: los problemas que las fuentes escritas plantean en el análisis etnohistórico. Sin embargo, tras asistir al resto

RDTP, LVIII, 1 (2003): 9-28 
de las sesiones, he pensado que para la publicación, tal vez sería de mayor utilidad rescatar un viejo escrito en el que relataba cómo abordé el estudio bibliográfico y el trabajo de campo en mi tesis doctoral dedicada a la Sierra Norte de Madrid. Con este texto que entonces denominé "metodología" se iniciaba mi trabajo y abrió también la principal publicación a que dio lugar (Fernández Montes 1990). Diez y seis años después, al releer estas páginas, sentí la tentación de realizar algunos cambios, pero tras sopesar ventajas e inconvenientes, he optado por dejar el texto tal y como fue redactado originariamente, introduciendo mínimas modificaciones en la puntuación, composición de alguna frase o palabra aislada, además de la inclusión de unas pocas notas a pie de página que actualizan o contradicen lo que entonces escribí, sólo cuando esta información pueda resultar de interés para el lector dentro del contexto de la nueva publicación en que ahora aparece.

Lo único que he añadido es la siguiente breve descripción de la comarca que ayudará al lector a situarse en el panorama general en el que desarrollé mi investigación.

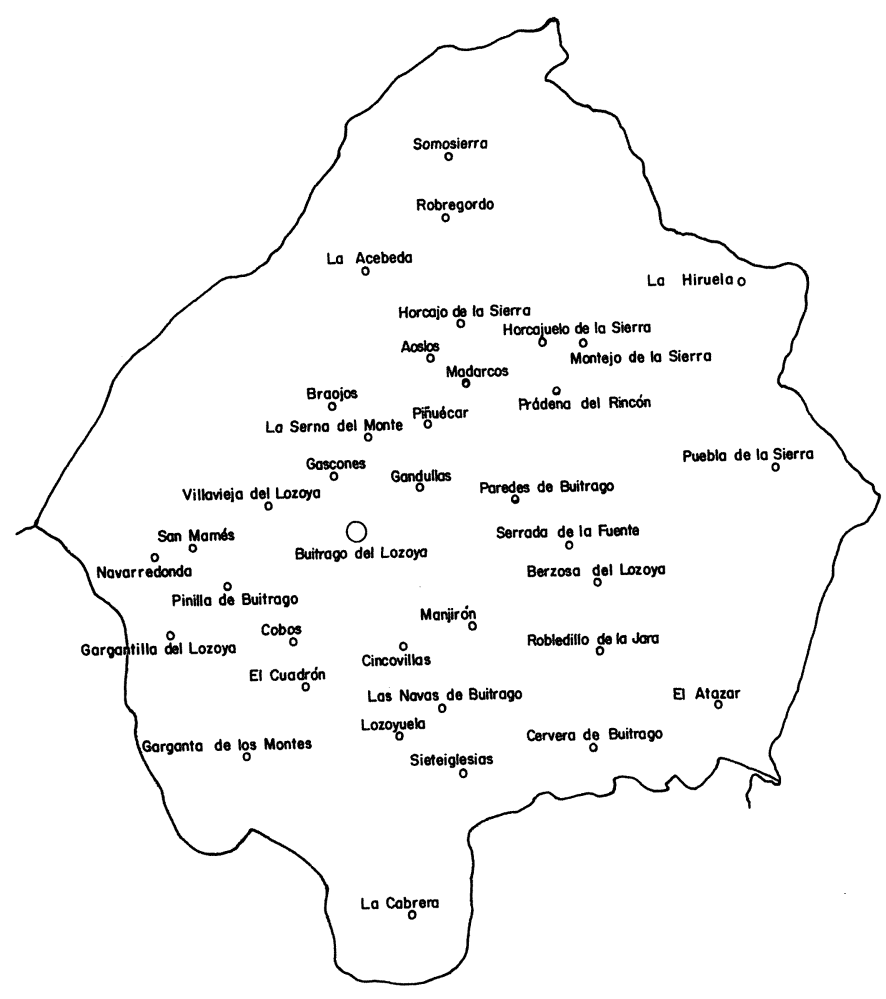

Figura 1.-Área de estudio. 
La comarca de Buitrago, también conocida como Sierra Norte o "Sierra Pobre", ocupa el extremo septentrional de la actual Comunidad de Madrid. Encuadrada en la vertiente sur del Sistema Central, con su vértice en el Puerto de Somosierra, dibuja una figura romboidal de $566,5 \mathrm{Km} .2$, el $8 \%$ del territorio madrileño. En 1980 contaba con 5.490 habitantes distribuidos en 36 pequeñas entidades de población, muy próximas entre sí y situadas en los terrenos más meridionales y benignos de sus respectivos términos municipales. Sus peculiaridades geográficas e históricas han dado una impronta característica a la zona. Al iniciarse la dominación cristiana del territorio se constituyó en Comunidad de Villa y Tierra que, tras vincularse a la Casa de los Mendoza como Señorío, alcanzó su mayor esplendor durante la Edad Moderna. De escasos recursos agrícolas por la pobreza de sus suelos y la frialdad de su clima, su economía siempre se ha basado en la ganadería ovina extensiva, comenzando su decadencia al iniciarse la crisis de los sistemas de producción tradicionales, ya con efectos palpables a la caída del Antiguo Régimen (abolición del régimen señorial, desamortización, abolición de la Mesta y hundimiento de las exportaciones laneras nacionales). La pérdida de protagonismo económico y social se agudizó aún más a partir de la década de los cincuenta del siglo XX, con el inicio de la industrialización en España y la mecanización y modernización de las explotaciones agrícolas, procesos a los que la comarca no pudo sumarse, viéndose sus habitantes abocados de forma masiva a la emigración.

En la actualidad es un caso típico de área rural de montaña deprimida, fuertemente afectada por la despoblación, con una población envejecida y escasas posibilidades intrínsecas de modificar esta situación. La revalorización del mundo y las tradiciones campesinas y la extensión del turismo rural se presentan casi como las únicas alternativas, aunque habría que sopesar muy cuidadosamente hasta qué punto estas nuevas formas de relación con el medio benefician a los vecinos autóctonos, o si sólo forman parte de las ofertas de ocio disponibles para los habitantes de la capital madrileña.

\section{Metodología EMPLEAdA EN EL ESTUdio ETNOGRÁFICO DE LA COMARCA DE BUITRAGO}

Me pareció necesario, al iniciar un estudio que fundamenta parte de su argumentación en el trabajo de campo, dedicar un capítulo a la explicación de la metodología empleada. En mi caso me siento especialmente obligada a ello, pues además de los condicionamientos que normalmente tienen este tipo de trabajos, desde que se concibió la idea de realizar un 
estudio etnológico en lo que entonces conocíamos como "La Sierra Pobre de Madrid" en 1979, hasta su conclusión y presentación, años después, se han ido sumando, durante su elaboración, nuevas circunstancias, que de forma inevitable se reflejan y han condicionado el resultado final.

Más que una metodología preconcebida y escrupulosamente aplicada, lo que aquí voy a contar son una serie de avatares y situaciones concretas de las que deliberadamente eliminaré todo adorno teórico. Probablemente a algunos estas líneas les podrían hacer dudar incluso de la validez científica del estudio, pero esto no me preocupa tanto como lo contrario, es decir silenciar o tratar de disfrazar lo que es evidente o incluso no siéndolo ha afectado el resultado final.

Aprovecharé la ocasión para hacer mi propia defensa de las directrices metodológicas, tanto en el trabajo de campo como en el bibliográfico y dar una explicación lo más amplia posible de su incidencia en aspectos o temas concretos.

A finales de 1979 se aunaron una serie de circunstancias que favorecieron la subvención oficial del trabajo de campo en etnología. Manuel Fernández-Miranda, que aquel año había sido nombrado Subdirector General de Arqueología, amplió las competencias de la Subdirección incluyendo la Etnografía en su epígrafe. Esto, entre otras cosas, posibilitaba extender por primera vez las ayudas que anualmente se concedían para la realizar excavaciones arqueológicas en España, a los trabajos de campo etnológicos.

En septiembre de ese año había leído mi tesina sobre el oficio de la hojalatería en Madrid y, apoyada por Manuel Fernández-Miranda, fue presentada a la Excelentísima Diputación Provincial para su publicación con el estudio del oficio de la tonelería, realizado como tesina por Carmen Ortiz García. Este organismo ya subvencionaba el trabajo de campo arqueológico en la provincia y, dada la favorable acogida con que recibieron nuestros estudios, parecía un buen momento para proponerles que ampliaran sus dotaciones a los estudios etnológicos. La Diputación, recién estrenado el mandato socialista y en un momento preautonómico, tenía una urgente necesidad de potenciar todo tipo de estudios provinciales y especialmente los de carácter antropológico, para justificar o al menos conocer, de alguna forma, las características de la vida tradicional en Madrid y no sólo en la capital, mucho más afectada por las transformaciones tecnológicas e industriales, sino sobre todo, en sus áreas rurales, en parte conservadoras de una personalidad cultural todavía no definitivamente borrada, a pesar de la fuerte amenaza que supone un núcleo urbano de tal envergadura a tan relativa poca distancia.

Por todo esto, y siempre apoyada por Manuel Fernández-Miranda, me introduje en un equipo compuesto por Eulalia Castellote —que había pu- 
blicado en la Diputación Provincial de Madrid un estudio sobre la cerámica de Camporreal-, Carmen Ortiz García, anteriormente mencionada y yo. Propusimos como área de estudio la llamada "Sierra Pobre de Madrid" pensando que elegíamos deliberadamente la zona más marginal de la provincia y que por ello tenía mayores posibilidades de conservar su carácter etnológico tradicional. Después de un breve viaje de reconocimiento y la elaboración de los subsiguientes informes preliminares que solicitaban ambos organismos, Diputación y Ministerio de Cultura, optamos, a falta de recursos económicos propios, a recibir las dotaciones económicas para comenzar el trabajo de campo. Éstas llegaron en otoño de 1980; sin embargo no eran el único impedimento que retrasaba el trabajo de campo: el equipo, compuesto de una forma coyuntural y apresurada, tenía pocas posibilidades de éxito. Cada una de nosotras desarrollaba en aquellos momentos de gran actividad, otros proyectos y trabajos que impedían casi totalmente una coordinación de tiempos reservados para el estudio etnológico de la "Sierra Norte". A pesar de ello, conseguimos robarnos una semana para la realización de trabajo de campo en la que Eulalia fue sustituida por María Ángeles Morcillo. En esta primera campaña, o quizás deberíamos decir precampaña, nos centramos en el estudio de la ganadería y la reconstrucción de las técnicas trashumantes que, practicadas hasta hace muy pocos años, se conservaban frescas en la memoria de los serranos.

Para mí, y creo que también para mis compañeras, resultó relevante encontrar una bolsa de pobreza y marginación tan cerca de la capital, pero a la vez tan alejada de ella en su modo de vida. Las posibilidades de un estudio de comunidad realizado con criterios clásicos eran prometedoras. De la misma manera las primeras tomas de contacto con la bibliografía específica abrían nuevas perspectivas. Fue en este momento cuando, de acuerdo con mis dos compañeras y los intereses personales de cada una, decidí hacer del estudio de la sierra el tema de mi tesis doctoral, responsabilizándome yo sola, a partir de entonces, de la realización y presentación del trabajo.

El invierno de 1981 lo dediqué a la investigación bibliográfica. En esta tarea me resultó valiosísima la ayuda y el apoyo recibidos del doctor Manuel Valenzuela, entonces profesor adjunto del Departamento de Geografía de la Universidad Autónoma de Madrid (hoy catedrático del mismo) y miembro del Instituto de Estudios Madrileños que había publicado su tesis doctoral, Urbanización y crisis rural en la Sierra de Madrid, en 1977, aunque basada en un área diferente a la mía. Sus orientaciones teóricas y metodológicas se vieron reforzadas con el ofrecimiento de los servicios de la biblioteca del Departamento. Ésta, además de ser una de 
las más completas en temas madrileños, resultaba especialmente valiosa al tener ficheros temáticos de los artículos publicados en las revistas a las que estaba suscrito'.

Tengo muy buenos recuerdos de esta etapa del trabajo. En ella fue cuando realmente me planteé las diversas posibles orientaciones o el mayor o menor peso de debían contener algunos capítulos. Creo que la influencia de la geografía ha quedado patente en apartados como los de evolución de la población, emigración, despoblamiento y urbanización o equilibrios desequilibrios entre sectores; pero, además de en estos temas, propios de la geografía humana, las orientaciones geográficas impregnan un poco toda la obra hasta el punto de que es probable que sea dentro de este campo donde más interés pueda despertar. La relación del hombre y el medio, el modo por el cual una unidad física de escasos recursos ha condicionado un tipo de poblamiento y economía, pero también cómo este poblamiento, dotado de una personalidad histórica, a su vez ha modificado ese medio, cómo a través de los siglos lo ha explotado, preservado y protegido, cómo ha sido utilizado por minorías frente a los intereses o necesidades generales, cómo ha incidido su posición geográfico-estratégica en los fenómenos de poblamiento y emigración históricos y actuales. No es posible establecer una línea demarcatoria entre unos y otros campos; todos han colaborado en la formación de una comunidad característica y peculiar. Conocida por varios nombres: "Sierra Pobre", "Sierra Norte", Tierra de Buitrago, comarca de Lozoya-Somosierra, partido de Buitrago, etc., es indudable que presenta una unidad geográfica, histórica y etnológica. Cada una de estas parcelas, consideradas globalmente o centrándose en temas concretos, son dignas de estudios independientes, pero están tan estrechamente trabadas que en ninguno de ellos se podría despreciar la posible incidencia de los otros dos aspectos.

Volviendo a la etapa de investigación bibliográfica desarrollada durante el invierno de 1981, fue una grata sorpresa encontrarme con una considerable cantidad de estudios monográficos de la zona, sobre todo en los campos de la geografía y la historia. La existencia en la sección de Osuna del Archivo Histórico Nacional, de los archivos de la Casa del Infantado, es una valiosísima fuente de datos sobre el área. Queremos mencionar algunas de las publicaciones más importantes o de las que hemos hecho un mayor uso, dejando antes patente que no se trata de

${ }^{1}$ En la actualidad, la Facultad de Geografía e Historia de la Universidad Autónoma ha agrupado todas las bibliotecas de los distintos departamentos en una de carácter general. 
una relación exhaustiva sino selectiva ${ }^{2}$ : con los datos del Catastro de Ensenada, contenidos en la sección de Osuna realizó un interesante estudio el Grupo 73 (1973) sobre la economía del Antiguo Régimen. El inventario de los bienes que los judíos dejaron en Buitrago, conservado en la misma sección de Osuna del Archivo Histórico Nacional, también ha generado un importante trabajo (Cantera Burgos y Carrete Parrondo 1972). Basándose en otras fuentes documentales, Jiménez de Gregorio (1975) ha publicado artículos y obras que nos dan una visión bastante completa por tratar independientemente todos los pueblos, sobre algunos aspectos geográficos y económicos.

Pero sin duda, la dedicación más constante y la aportación documental de mayor envergadura, proceden de Matías Fernández García que, desde 1963 , se ha dedicado al estudio de Buitrago y su tierra realizando numerosas publicaciones sobre la comarca. Matías Fernández, natural de Montejo de la Sierra, representa un modelo ejemplar del erudito local con un método y rigor histórico del que muchos deberían tomar lecciones. Quiero destacar dentro de su producción las Fuentes para la bistoria de Buitrago y su Tierra (Fernández García 1966), tanto por su valor intrínseco como por su constante utilización en mi trabajo. En ellas se publican todo tipo de documentos: ordenanzas del Señorío de Buitrago, de municipios, de bosques, de cofradías religiosas, etc., obtenidos de la paciente transcripción de las fuentes halladas, tanto en los archivos municipales y parroquiales de los pueblos del antiguo Señorío de Buitrago, como de la citada sección de Osuna del Archivo Histórico Nacional.

Al reverendo Matías Fernández García se le pueden reprochar errores imperdonables, como que no siempre quede claro dónde se halla el original de las fuentes transcritas. En líneas generales sus obras resultan más descriptivas y aportadoras de datos que interpretativas, pero, en cualquier caso, son una fuente de información imprescindible y difícilmente superable con la que deberá contar cualquier estudio sobre la sierra de Buitrago.

La abundancia de las fuentes documentales y bibliográficas a partir del siglo XVI, superaba con mucho los límites de mis propósitos en los campos estrictamente geográficos e históricos. Para no perderme en áreas de donde me resultara difícil salir, decidí no realizar personalmente la labor de archivo restringiéndome a la consulta de las fuentes y estudios publicados.

${ }^{2}$ Desde que se redactaron estas líneas en 1987 a la actualidad, se han multiplicado los estudios y publicaciones sobre la Sierra Norte, tanto históricos y geográficos como antropológicos, aunque en esta publicación no los mencionaré como tampoco enumeraré la bibliografía completa que acompañaba a la obra general. 
Durante el invierno de 1981 comencé también la realización de trabajo de campo. En esta época los viajes fueron bastante distanciados y esporádicos, normalmente de un solo día de duración. Traté de realizar al menos uno a cada localidad como toma de contacto, previa al verdadero trabajo de campo. En estas visitas que se intensificaron cuando pude disponer de un vehículo, a partir de Semana Santa, procuraba entablar conversación en el bar del lugar con las personas que se hallaran allí en el momento, cosa bastante fácil, dada la curiosidad natural de sus habitantes ante una persona desconocida. Explicaba mis propósitos lo más claramente posible y en muchas ocasiones realizaba pequeñas encuestas sobre temas concretos (pastoreo, tejido del lino, cestería, arrieros, fiestas, etc.), casi como una ilustración gráfica hacia los aldeanos de lo que podían ser temas de interés en mi investigación. Siempre preguntaba también por el número de vecinos y las posibilidades de encontrar alojamiento durante un año. En estas primeras visitas no tomaba notas por escrito, ya que mi principal propósito no era la documentación etnográfica sino, sobre todo, se trataba de una toma de contacto de carácter global. A la salida del pueblo realizaba una o varias fichas en las que relataba la impresión general que me había producido el municipio, si estaba poco o muy urbanizado, si conservaba la arquitectura popular, dimensiones, etc. Además procuraba anotar cómo había sido acogida (reticencia, cordialidad, etc.) y el tipo de información etnográfica recibida (posibles artesanías, técnicas ganaderas y agrícolas...) Con estos apuntes realicé un fichero lo más completo posible de temas y pueblos. De forma paralela comencé el acopio de documentación gráfica que en esta etapa, se centró en la arquitectura popular y, en menor medida, en aperos o algunas instalaciones tradicionales para el ganado, siempre procurando no importunar a los habitantes.

Interrumpidas estas tareas durante los meses estivales, las reanudé en septiembre ya con el propósito firme de establecerme todo un año en alguna de las localidades. Dada la cercanía de la Sierra Norte a la capital, podría haberme planteado realizar el trabajo de campo a través de campañas intermitentes sin instalarme en la zona. Sin embargo, me parece más acertada la primera solución, sobre todo siendo mi intención la de desarrollar una investigación etnológica de carácter global. Si ciertamente para la documentación de determinados oficios u otros aspectos tecnológicos o incluso sociológicos o animológicos aislados, puede ser suficiente la encuesta cerrada en visitas aisladas, el verdadero carácter de la vida cotidiana sólo se conoce cuando se convive y, con mayor o menor fortuna, se logra ocupar un puesto dentro de la comunidad (no me refiero aquí a una verdadera integración, problema mucho más complejo del 
que trataré más adelante), conociendo sus rutinas y hábitos, los diferentes tipos sociales, el papel de las autoridades, el mayor o menor peso de los grupos de edad, etc.

Un año es el tiempo mínimo ideal para este tipo de trabajos, ya que así se tiene oportunidad de tomar contacto con los diversos ciclos anuales, los cambios estacionales de ocupación, ritmos agrícolas, ganaderos, fiestas, etc.

La elección del pueblo y la vivienda donde me instalaría corrió el riesgo de ser un problema sin solución. Durante los meses de septiembre y octubre fue el motivo principal de la mayoría de mis viajes y entrevistas. Por una parte la oferta de casas en la zona es realmente escasa, aunque existe un elevado índice de despoblación y muchas se hallan vacías, los propietarios no son partidarios de ningún tipo de enajenación que pueda cuestionar el hipotético futuro disfrute de la propiedad, aunque ésta lleve muchos años desocupada. Muchos la reservan para sus hijos emigrados, otras son producto de la herencia de varios hermanos a los que es imposible, no ya poner de acuerdo, sino tan siquiera localizar. De algunas tuve que desistir porque, al llevar abandonadas muchos años, carecían de los servicios mínimos (agua y electricidad), otras por el contrario, se habían rehabilitado con vistas al "turismo de fin de semana" pidiéndose por ellas mensualidades que excedían mi presupuesto.

A todo esto se sumaban mis preferencias por unas u otras localidades. Después de visitados todos los pueblos y de las primeras tomas de contacto, para mí era patente que en ningún caso podría centrar mi estudio en un solo núcleo urbano. Estos, exceptuando Buitrago, Lozoyuela y La Cabrera, tienen una media muy baja de habitantes (de treinta a doscientos), demasiado pocos para pretender hacer generalizaciones válidas para toda la sierra. Con estos planteamientos no me interesaba instalarme en ninguno situado en los extremos o mal comunicado, ya que continuamente me vería obligada a largos desplazamientos que la estación invernal y el mal estado de la red viaria desaconsejaban. Por otra parte, los núcleos de una cierta importancia, como Buitrago, capital tradicional de la Sierra Pobre, con unos mil habitantes, o La Cabrera y Lozoyuela que habían crecido de forma desmesurada, favorecidos por su situación en la Nacional I, conservaban en mucha menor medida su carácter tradicional; en buena parte han sido remodelados, la actividad de sus habitantes ha abandonado el esquema tradicional para descompensarse hacia el sector de servicios y, finalmente, están profundamente afectados en su estructura por los fenómenos migratorios-inmigratorios.

Lo ideal para mí era un pueblo que estuviera cercano a Buitrago, tanto por ser la capital de la comarca y más o menos su centro geográfico, 
como por estar situado en la Nacional I, lo que facilitaría mis desplazamientos al resto de las localidades.

Con el fin de paliar la natural desconfianza hacia el intruso, yo había procurado presentarme a los alcaldes de los pueblos visitados contando mis propósitos y solicitando su colaboración en la búsqueda de la vivien$\mathrm{da}$, pero sin duda fue mucho más decisiva mi amistad con Teresa Vallejo entonces médico titular de Buitrago y sus anejos; el hecho de haber ido con ella en algunas de mis visitas y su presentación como "persona de confianza" tuvo un efecto mucho más eficaz que todas mis explicaciones $\mathrm{y}$ presentaciones.

Al fin, y ante las numerosas dificultades que se me planteaban, me decidí por un tipo de oferta que me habían realizado en varios pueblos. Se trataba de compartir la vivienda, normalmente de dos pisos, con su propietario, en general una persona anciana que vivía sola. Yo ocuparía el piso de arriba y el propietario el de abajo. El anciano buscaba en esta solución un poco de compañía, a mí podía favorecerme, ya que si entablábamos una buena relación sería una valiosa ayuda como informante y, además, de alguna forma, podía actuar de puente entre mi persona y el resto de la población. De este tipo de ofertas elegí la de doña Rosa Ramírez (entonces con 78 años), establecida en Manjirón ${ }^{3}$. El pueblo tenía la ventaja de su cercanía a Buitrago y su relativamente alto número de población (unos doscientos habitantes entre los que, gracias a la pequeña oferta de trabajo en el Canal de Isabel II, estaban representados todos los grupos de edades).

Así, al iniciarse noviembre, me instalé en la citada localidad. La casa que compartía con doña Rosa Ramírez es de muy grandes proporciones. Aunque sus dos pisos están comunicados por una escalera interior, el segundo tenía también una entrada independiente desde el exterior y cocina y cuarto de baño propios (había sido acondicionada de esta manera para alojar con mayor comodidad a sus hijos y nietos cuando iban a pasar allí las vacaciones veraniegas). Estaba claro que, pese a la teórica independencia, Rosa y yo debíamos entablar algún tipo de relación mayor a la usual entre caseros e inquilinos. Desde el primer momento fueron afectuosas y cordiales. Con cierta frecuencia yo me bajaba a conversar con ella y varias amigas que periódicamente se reunían por las tardes.

\footnotetext{
${ }^{3}$ Existe una cierta imprecisión sobre la ortografía de este nombre. Hasta el siglo XX aparece siempre Mangirón con "g" y a partir de esta fecha empieza a aparecer con "j", grafía que predomina en la actualidad, aunque todavía se puede encontrar escrito el nombre de la localidad con "g". En el estudio opté por escribir siempre Manjirón, excepto en las citas textuales en que respeté la grafía original.
} 

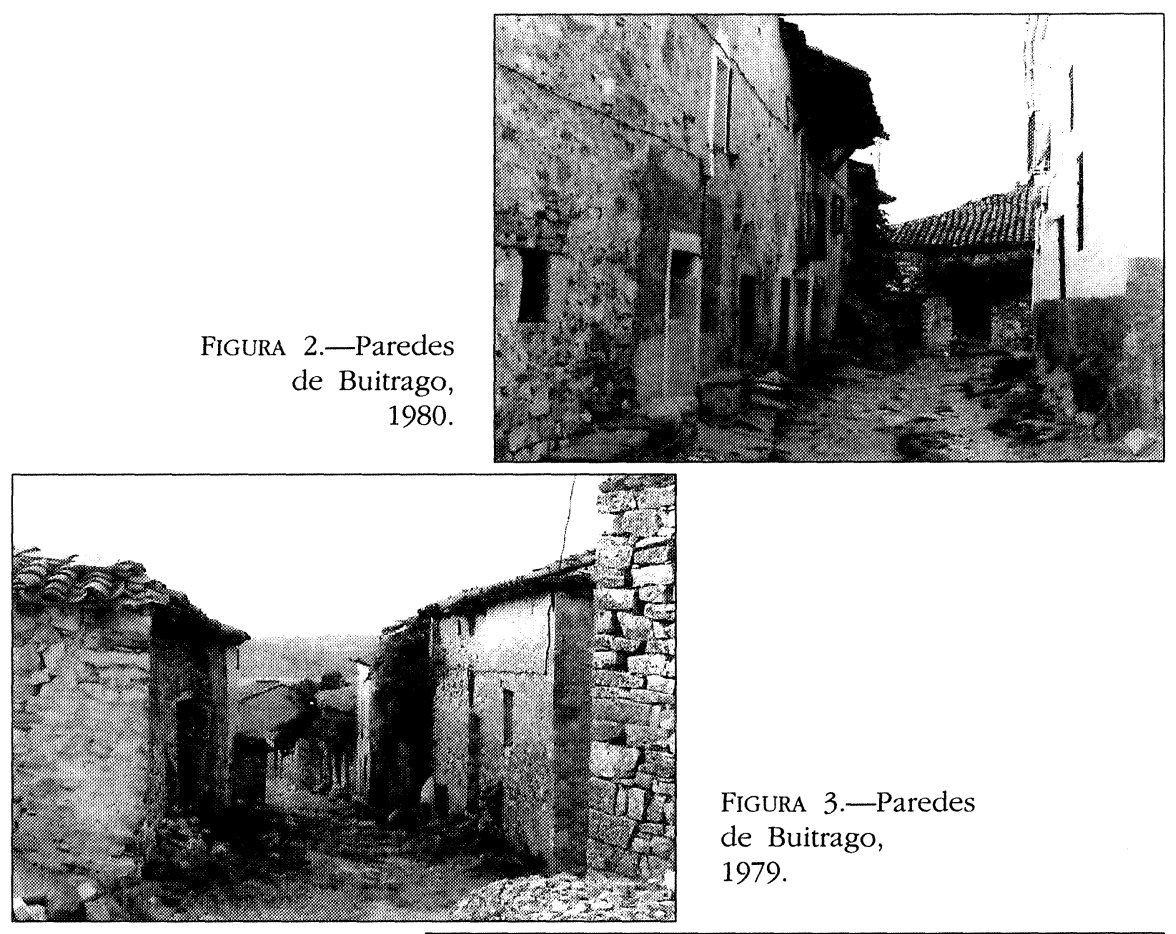

Figura 3.-Paredes

de Buitrago,

1979 .

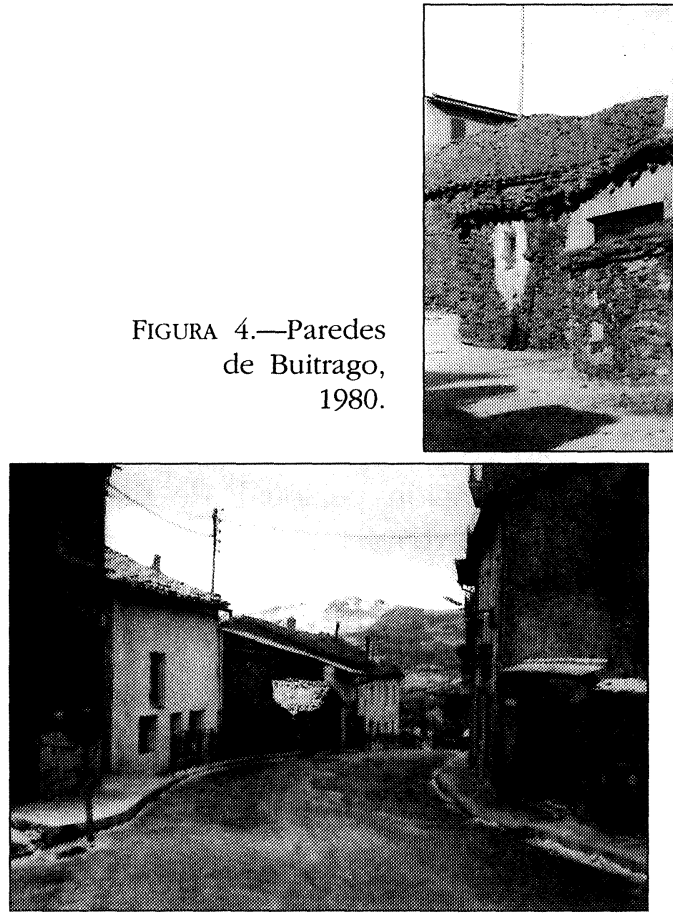

FIGURA 5.-Montejo

de la Sierra,

1981. 
También a veces comíamos juntas o yo le traía algún producto que necesitaba de Buitrago. Como informante me prestó una ayuda incuestionable, aunque todas sus conversaciones, antes o después pero de forma inevitable derivaban hacia sus dos hijos (ambos emigrados), nueras y nietos.

Pensando retrospectivamente en los seis meses que compartimos la vivienda, creo que en el fondo tanto ella como yo quedamos algo decepcionadas de la experiencia. Rosa buscaba en mí la reencarnación de una maestra que en circunstancias parecidas había convivido quince años con ella. Su moral (no olvidemos que tenía 78 años) era muy estricta. Aunque nunca me lo manifestó, estoy segura de que desaprobaba muchas de mis salidas, sobre todo cuando ya había anochecido (en aquella época del año a las seis de la tarde). Tampoco le parecía adecuado que una mujer sola entablara conversación con hombres y mujeres de todas las edades y clases sociales. Por otra parte, me resultaba bastante gravosa su continua vigilancia de todos mi movimientos, la falta de independencia y el sometimiento o determinadas concesiones que con frecuencia debía realizar.

No se debe pensar por esto que la experiencia fue un fracaso o que tuvimos algún tipo de roce manifiesto. De hecho, y no sólo hablando en el terreno exclusivo del trabajo, fue altamente beneficiosa, tanto por la información directa que obtuve, como también porque, al estar alojada en su casa, se disiparon muchas reticencias de otros habitantes y de alguna manera contribuyó de forma decisiva a que yo fuera situada dentro de la comunidad en un status respetable, bien diferenciado de las tan mal vistas "comunas de hippies" o de los turistas de fin de semana. Si en el terreno personal me hubiera encontrado más cómoda y libre en una vivienda independiente, con toda probabilidad habría tropezado con algunas dificultades en el trabajo que se solucionaron de forma automática con esta fórmula.

La etapa de trabajo de campo intensivo fue una experiencia en la que de alguna forma puse a prueba no sólo conocimientos o planteamientos teórico-metodológicos sino toda mi capacitación personal; de mi habilidad para introducirme en la comunidad y extender el trabajo de campo a unas $u$ otras facetas dependía en gran parte el éxito o fracaso de todo el proyecto (al menos en aquella época así me lo planteaba). El inicio de mi estancia en Manjirón y, de forma más o menos amortiguada, todo el período fue de una gran dureza. Instalada sola en la sierra, más que comprender, sentí hasta qué punto se trataba de dos mundos culturales diferentes y de difícil comunicación fuera de determinados terrenos. De hecho, mi amistad con algunos médicos y maestros que ejercían en la zona, aunque normalmente procedían de Madrid, y los buenos ratos pa- 
sados con ellos, fueron los únicos momentos en los que yo me mostré de una forma espontánea sin necesidad de sopesar constantemente la imagen que pudiera dar.

Durante esta etapa y siguiendo planteamientos clásicos, elaboré un diario en que anotaba mi actividad: las personas y los temas de los que había hablado, posibles citas con informantes de interés en aspectos concretos, etc. También procuraba describir mis sentimientos y los sucesivos estados de ánimo que en mí despertaban personas y situaciones. Releyendo estas páginas muchos problemas y soluciones de tipo metodológico salen a la luz. Voy a exponer algunos de ellos siguiendo aproximadamente el orden cronológico en que aparecen. En la mayoría de los casos son resoluciones personales, en lugares concretos, a situaciones muy determinadas que difícilmente podrían extrapolarse. Pero pienso que, además de ser una información útil sobre las circunstancias que acompañaron al trabajo de campo, puede resultar orientativa sobre algunos planteamientos y problemas clásicos en los trabajos etnológicos de comunidades rurales en España.

En primer lugar quiero destacar que toda la serie de tomas de contacto y viajes previos me fueron de gran utilidad. En la mayoría de estos pueblos la aparición de un intruso entre semana y las conversaciones con él sostenidas, pueden ser acontecimientos de suficiente novedad como para ser recordados durante un largo período de tiempo, máxime si la visita se repite dos o tres veces. Así, cuando me instalé en Manjirón, no estaba totalmente sola ni desorientada; aparte de la abundante información bibliográfica que conocía, eran muchas las personas que tenían noticia de mí y a las que yo podía acudir para determinadas cuestiones. También contaba ya con fichas preliminares sobre los pueblos, la acogida que en ellos había recibido y los temas tocados.

Uno de mis problemas fundamentales era el deseo de dar a mi estancia en la sierra una apariencia de verdadera actividad laboral entre sus habitantes. Quería que de alguna forma me aplicaran un status como profesional, aunque ellos no contaran con un oficio semejante. En este sentido fue de gran utilidad mi vinculación con la Excelentísima Diputación Provincial de Madrid (una de las entidades financiadoras) y las cartas de presentación que me facilitaron. La Diputación representaba en la sierra la principal institución exterior. Con mayor o menor frecuencia, pero de manera palpable financiaba algunas mejoras o acometía inversiones. Era el único organismo al que acudían los alcaldes de la zona como autoridad ejecutiva superior. En realidad y de forma bastante desmesurada resultaba omnipresente y omnipotente en la mentalidad de los pueblos serranos. De ella, para bien o para mal, se podía esperar cualquier acto u omisión que transformara la vida cotidiana, desde la canalización 
y acometida del agua o la mejora de explotaciones ganaderas, a la concesión de becas de estudios o la subvención de fiestas locales. Como es obvio, el empeño que puse en mencionar y enseñar las cartas de presentación, de forma inmediata acrecentó la respetabilidad de mi tarea. Por otra parte, en varias ocasiones, la Diputación había emprendido estudios de uno u otro tipo en la comarca. En aquella misma época un equipo de arquitectos visitaba iglesias parroquiales y edificios municipales para elaborar un informe sobre su estado de conservación y riqueza artística. Fui asimilada a este tipo de profesionales "mandados por la Diputación".

Dado el elevado número de efectivos de la Guardia Civil establecidos en Buitrago y los controles que con cierta frecuencia se realizaban en la Nacional I, me pareció conveniente para facilitar sus investigaciones y evitarme posibles problemas, comunicar a este cuerpo mi instalación en Manjirón, los propósitos y circunstancias del proyecto y la frecuencia de mis desplazamientos por la sierra.

Al iniciar de forma efectiva el trabajo y en parte a favor de la búsqueda de un "status profesional", dediqué muchas de las mañanas de los primeros meses a la consulta de las hojas de empadronamiento y otros documentos que existían en los ayuntamientos. Así, además de completar un censo de la población y obtener la valiosa documentación sobre movimientos migratorios, grupos de edades, actividades profesionales, nivel de instrucción, etc., tenía la oportunidad de entablar conversación con secretarios, alcaldes y otros transeúntes habituales que comprendían mejor mi actividad laboral ante una mesa y unos papeles que en una posible charla ante el hogar, por poner un ejemplo. Para el desarrollo de esta actividad me vi obligada a acoplarme a los días en que los secretarios trabajaban en cada municipio, pues al ser normalmente titulares de varios, debían repartirse entre unos y otros.

Durante toda mi estancia en la sierra fui objeto de una atención más o menos indiscreta que traté de aprovechar para aclarar al máximo el carácter de mi trabajo y empezar a trabar conocimiento con individuos concretos, sus características familiares, sociales y profesionales. Desde el primer momento procuré no hacer incómoda mi presencia buscando para las entrevistas momentos en que no interrumpiera sus actividades o, ante la necesidad de documentarlas, practicando la denominada "observación participante". Traté de irme introduciendo en las tertulias y reuniones desempeñando un papel secundario y sólo cuando tenía alguna garantía de éxito proponiendo temas de conversación o preguntas concretas, de las que sólo en ocasiones tomaba notas por escrito en el momento. El siguiente paso consistió en establecer citas con individuos representativos para la realización de entrevistas más sistemáticas. 


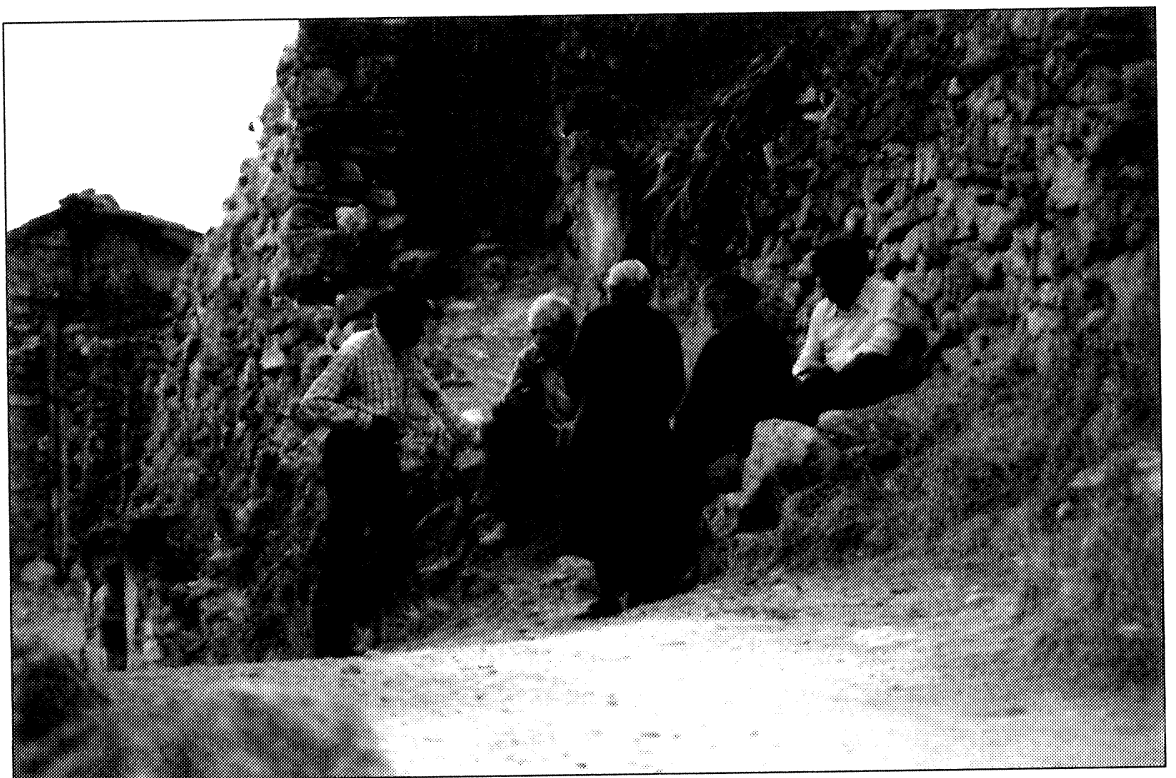

FIgURA 6.-Tertulia en la calle, 1979.

Los lugares y horarios de reunión de varones y mujeres, niños, jóvenes, adultos y ancianos varían. Los ancianos de ambos sexos, en la medida de sus posibilidades, trabajan y colaboran con las tareas familiares, pero, por la disminución de su actividad, es fácil encontrarlos en invierno, solos o acompañados, junto al hogar. En líneas generales son muy asequibles y propensos a largas conversaciones. Los hombres adultos se reúnen en los bares una vez finalizado el trabajo, normalmente por la noche, y éste es el momento en que son fácilmente abordables. Las mujeres adultas por lo general no tienen citas ni tan conjuntas ni tan precisas, lo que no significa una falta de relación. Una tertulia puede formarse entre las componentes de una cola de espera ante un vendedor ambulante, cosiendo a la puerta de una casa, en el lavadero, etc. Los grupos de jóvenes y niños en la Sierra Norte sólo tienen cierta importancia en Buitrago, Lozoyuela y La Cabrera, ya que en el resto de las localidades y sobre todo entre semana, su número es demasiado reducido y por la falta de centros adecuados (escuelas, discotecas y bares) normalmente se desplazan a Buitrago, tanto para su escolarización, como los mayores para su diversión y relación. La comunicación con el grupo de jóvenes, por la similitud de edad, fue la que menos problemas me planteó. Conocía los centros y horarios en que se podían encontrar en Buitrago y me asimilaba a ellos de una forma bastante natural. Para 


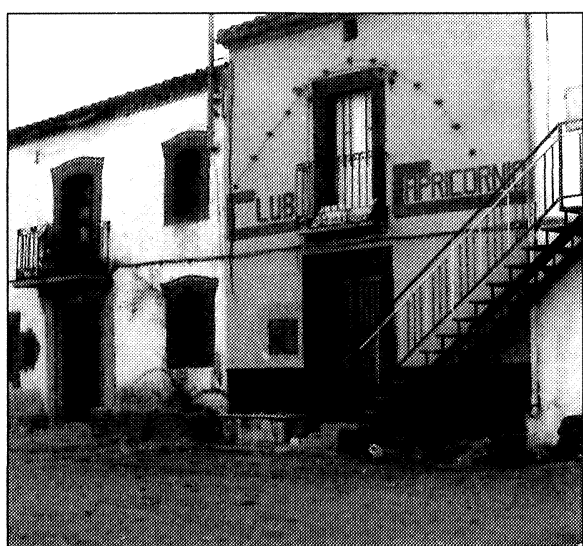

FIGURA 7.- "Puticlub" en la Venta de la Gamera, 1980.

ponerme en contacto con la mentalidad infantil me valí de unas redacciones encargadas a través de una maestra de las Escuelas $\mathrm{Na}$ cionales de Buitrago, a niños de diversos pueblos y cursos que versaban sobre su familia y "el día más importante del año".

Como es normal en todos los ámbitos sociales, el trato con determinadas personas está mal visto o excluye el de otras. Más que la clásica división por clases sociales se trata de rivalidades entre grupos de individuos o familias que se acentúan todavía más entre unos y otros pueblos. Como es lógico traté de mantenerme al margen y no dejarme encasillar dentro de determinados sectores.

Enlazando con esto me veo obligada a detenerme en un tema de vital importancia, el sexo, la edad y el estado civil del investigador solitario condicionan en buena parte las relaciones que se establecen con unos y otros grupos. Al ser una mujer joven y casada me resultaba relativamente fácil hablar con otra de similares circunstancias sobre la educación de sus hijos, los sistemas anticonceptivos o incluso los encantos y desencantos de su vida conyugal, temas que difícilmente podría abordar un investigador masculino. Como contrapartida, al relacionarme con los grupos de hombres encontré serias dificultades, por ejemplo, para dar visos de normalidad a mi presencia en un bar donde sólo había miembros del sexo opuesto. Para tratar de paliar este problema, en mis escasas visitas nocturnas al bar de Manjirón procuré ir acompañada por el alcalde o algún otro conocido. Esto no impidió por supuesto que en cierta forma fuera una intrusa delante de la cual nunca se desarrollarían determinadas situaciones "sólo para hombres". Aunque, desde el primer momento, intenté que la comunidad no me aplicara sus esquemas sobre el comportamiento propio de varones, hembras, solteros y casados, ésta lo hizo de forma inevitable acercándome y alejándome de unos y otros.

Esta problemática en el trabajo de campo, en mi caso ha quedado en parte atenuada, gracias a la colaboración de Carlos Laffón Roca con el que entonces estaba casada, que, pocos días después de mi partida de la sierra, se instaló como médico titular de Villavieja de Lozoya. A él se deben informaciones, sobre, por poner un ejemplo extremo, el funcionamiento, 
ambiente y tipo de visitantes de los llamados "bares de carretera" en los que hubiera estado muy mal vista mi presencia.

Sin duda el tipo de reunión heterodoxa de la que más información obtuve y a la que más asiduamente acudí fue la que se forma en los bares o también en casas particulares frente al hogar, durante las tardes o las mañanas, en momentos de poca actividad o entre personas jubiladas.

Quien haya tenido la paciencia de leer estas páginas, se habrá dado cuenta de que, al hablar de la sierra, continuamente aludo al frío, los hogares y el invierno como si no hubiera conocido otra estación. Y es que mi estancia, planteada para un año, se vio bruscamente interrumpida a causa de un accidente de tráfico, a finales de marzo de 1982. A consecuencia de él y después de tres años de rehabilitación ininterrumpida, el primero de ellos ingresada en un centro especializado en Toledo, me veo obligada a utilizar silla de ruedas en la mayoría de mis desplazamientos.

En los primeros meses que siguieron al accidente, a pesar de lo precario de mi estado físico no abandoné el proyecto. Para no interrumpir del todo el ritmo de acopio de datos, conté con la colaboración de Joaquín Fernández Montes y Carlos Laffón Roca. El primero, entonces estudiante de cuarto curso de Geografía e Historia, recibió hasta septiembre de 1982, un salario procedente de los fondos.que todavía me quedaban, continuando con la investigación bibliográfica. Este tiempo lo dedicó a la

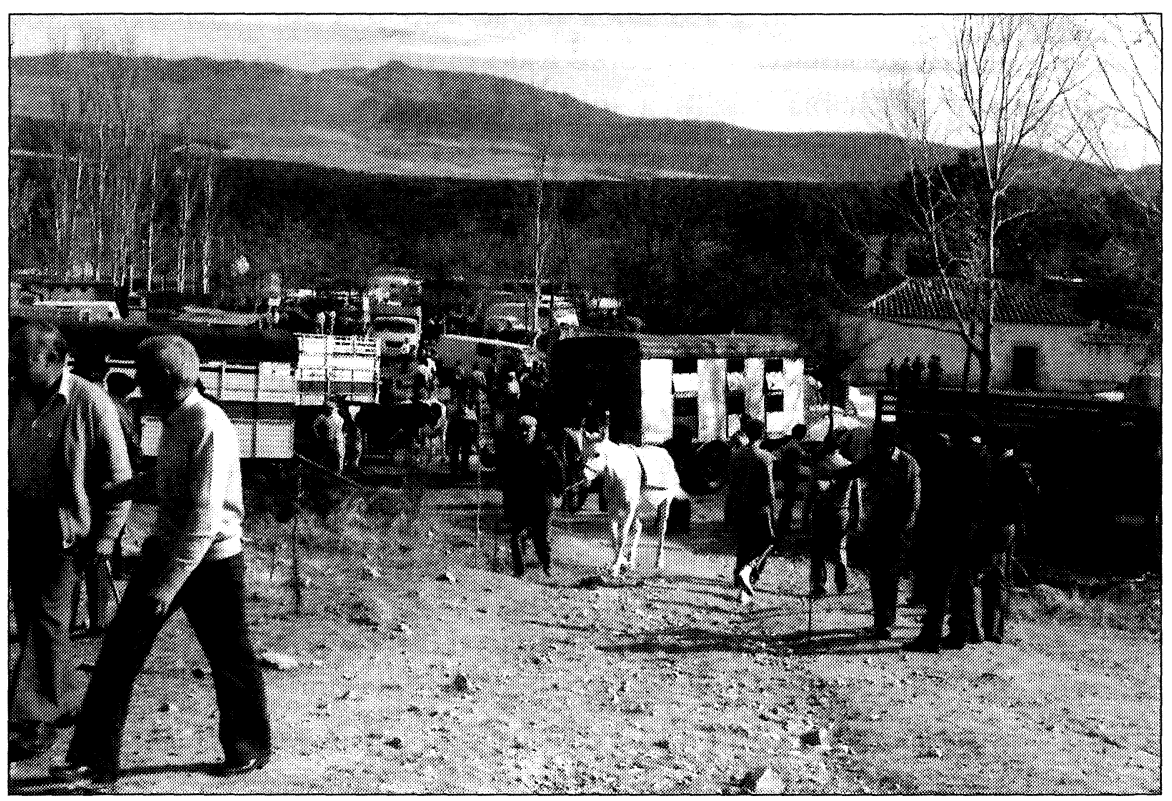

FIGURA 8.-Feria de ganado en Buitrago, 1980. 
confección de fichas de contenido sobre los pueblos del área de estudio, vaciando obras clásicas como las de Larruga y Boneta (1787), Madoz (18261850), Miñano y Bedoya (1826-1828), el Diccionario Geográfico de España (Bleiberg, Cabo Alonso y Quirós 1956-1961), Ortega Rubio (1921) y Colmenares (1969-70), además de muchas otras de menor incidencia que completaron sobre todo el panorama histórico. Carlos Laffón que, como ya he mencionado, ejerció durante un año y medio (abril de 1982-septiembre de 1984) como médico titular de Villavieja de Lozoya, me ha proporcionado multitud de datos de todo tipo durante su permanencia en la sierra y sus frecuentes visitas posteriores. Gracias a él mantengo aún contactos personales con algunos de los habitantes de la comarca.

Periódicamente "mis nuevos ayudantes" me visitaban a Toledo trayéndome, sobre todo el primero, la documentación obtenida. En teoría durante esta etapa yo procuraría dedicar parte de mi tiempo a la ordenación y clasificación del material para la posterior redacción del estudio, pero a los graves problemas físicos y síquicos con los que me enfrentaba, se sumó mi total incomunicación con los organismos subvecionadores y en general con todo mi antiguo mundo profesional. El ritmo de trabajo languideció hasta interrumpirse definitivamente en otoño de 1982.

Tres años más tarde el asunto parecía definitivamente liquidado, los antiguos organismos subvencionadores habían transferido sus competencias a la recién estrenada Comunidad Autónoma de Madrid, de forma que, hasta donde conozco, en estos años no se volvió a subvencionar el trabajo de campo etnológico, pero sobre todo el mío se consideraba un caso liquidado. Yo no había vuelto a tener ningún tipo de contacto con las personas que en otras épocas me ayudaron u orientaron y las imaginarias expectativas profesionales que en su día me animaron a emprender la realización de mi tesis doctoral parecían haberse esfumado de forma irreversible.

El material, fruto de las etapas de trabajo anteriores, permanecía arrinconado en unos cuantos cajones, de una forma bastante desordenada e inconexa. Sin embargo, no tuve el valor suficiente para deshacerme de aquellos papeles renunciando de forma definitiva a su elaboración. Este trabajo incompleto y las nefastas repercusiones que para mí había tenido pesaban demasiado en mi vida.

En marzo de 1985, alentada por un breve devaneo profesional, adquirí el firme propósito de ordenar y redactar una memoria con todo el material acopiado sobre la Sierra Pobre. Cuando tomé esta decisión no existía ninguna causa o perspectiva concreta, quizá fue sólo porque estoy acostumbrada a terminar las cosas que inicio o por la conciencia íntima de que mis limitaciones físicas no eran suficiente justificación para renun- 
ciar al proyecto. Por otra parte, no quería asumirlo como un fracaso. Pero sobre todo, con mi vuelta a la documentación sobre la sierra de Buitrago, pretendía liquidar una etapa. De alguna manera el transformar esos cajones con papeles desordenados en una memoria coherente, susceptible de ser juzgada, era la única forma de acabar definitivamente con los reencuentros periódicos. Se trataba de poner un punto y aparte para acabar con tantos puntos suspensivos. Hasta que no me liberara de esta carga no podría normalizar mi vida profesional a los mínimos niveles.

La etapa final de elaboración de los datos ha sido la más dura. En condiciones menos favorables que en las primeras fases, me he visto obligada a compaginar este trabajo con otras tareas laborales que han alargado más de lo deseado el período de redacción.

Comencé desempolvando viejos papeles, con una revisión de todo el material que poseía, bibliográfico y de campo. Con estos datos compuse un esquema provisional en el que quedaban patentes algunos vacíos en la documentación, además de la necesaria actualización bibliográfica. Lo más problemático para mí era completar los datos de campo, interrumpidos demasiado bruscamente. Ante la falta de subvención y mi necesidad de trabajar en Madrid, desistí de realiżar una campaña sistemática procurando solventar, con algunas excursiones y llamadas telefónicas, los huecos más sobresalientes. Para la primera labor he contado con la colaboración desinteresada de Carlos Laffón Roca, sin cuya ayuda no hubiera podido llevarla a cabo. Sin duda esta segunda fase de documentación, paralela a la propia redacción, no ha sido tan exhaustiva como hubiera debido, aunque nunca, ni con el trabajo de campo ni con el bibliográfico se puede pretender decir la última palabra. Creo que el estudio elaborado es una aportación al conocimiento de la comarca de Buitrago y a las comunidades de montaña en el Sistema Central dentro de una visión antropológica diacrónica, pero deberá ser completado y superado con investigaciones posteriores.

\section{BIBLIOGRAFÍA CITADA}

Bleiberg, Germán, Ángel Cabo Alonso y Francisco Quirós. 1956-1961. Diccionario geográfico de España. 17 vols. Madrid.

Cantera Burgos, Francisco y Carlos Carrete Parrondo. 1972. "La judería de Buitrago". Sefarad XXXII: $1-54$.

Colmenares, DiEgo DE. 1969-70 [1637]. Historia de la insigne ciudad de Segovia y compendio de las historias de Castilla. Segovia: Academia de Historia y Arte de San Quirce. 
FERnÁNDez GarCía, Matías. 1966. Fuentes para la bistoria de Buitrago y su Tierra. Madrid.

FERNÁNDEZ MONTES, MATILDE. 1990. Cultura tradicional en la comarca de Buitrago. Madrid: Patronato Madrileño de Áreas de Montaña. Comunidad de Madrid.

GRUPO 73. 1973. La economía del Antiguo Régimen. El Señorio de Buitrago. Madrid: Universidad Autónoma de Madrid.

JiméneZ DE GREgorio, Fernando. 1975. "Los pueblos de la tierra de Buitrago en las descripciones de Lorenzana. 1782". Estudios Geográficos XXXVI: 551-566.

LARRUGa Y BONETA, EUgENIO. 1787. Memorias políticas y económicas sobre los frutos, comercio, fábricas y minas de España. 45 vols. Madrid.

MADOZ, PASCUAL. 1839-1850. Diccionario geográfico-estadístico-bistórico de España y sus posesiones de Ultramar. Madrid.

MiÑANO Y BEDOYA, SEBASTIÁN. 1826-1828. Diccionario geográfico-estadístico de España $y$ Portugal. Madrid.

Ortega Rubio, Juan. 1921. Historia de Madrid y los pueblos de su provincia. Madrid. VAlenZuela RuBIO, MANuel. 1977. Urbanización y crisis rural en la Sierra de Madrid. Madrid: Instituto de Administración Local. 